\title{
SOBRE A IMPORTÂNCIA DA SENSIBILIDADE PARA A AÇÃO ÉTICA
}

\author{
On the importance of sensitivity for ethical action
}

\author{
Michelle Bobsin Duarte \\ UFRRJ
}

\begin{abstract}
Resumo: O presente trabalho tem como objetivo aprofundar a compreensão sobre a importância da sensibilidade nas ações éticas, segundo a filosofia de Hans Jonas. A sensibilidade possui um lugar de destaque no pensamento de Jonas, já que o autor considera tanto o âmbito racional do ser humano quanto o sensível como essenciais à uma proposta ética que seja efetiva. Assim, para compreendermos de maneira mais apurada a relação da sensibilidade com a ética no pensamento do filósofo, faremos uma análise dos afetos em $O$ Princípio Responsabilidade com a finalidade de mapear as suas potencialidades e as conexões com a ética.
\end{abstract}

Palavras-chave: Ética; Afetos; Sensibilidade; Hans Jonas

\begin{abstract}
This work aims to deepen the understanding of the importance of sensitivity in ethical actions according to Hans Jonas' philosophy. Sensitivity has a prominent place in Jonas's thinking, since the author considers both the rational scope of the human being and the sensitive as essential to an ethical proposal that is effective. Thus, in order to better understand the relationship between sensibility and ethics in Jonah's thought, we will make an analysis of affections in The Imperative of Responsibility, in order to map the affective potentiality and connections with ethics.
\end{abstract}

Keywords: Ethics; Affection; Sensitivity; Hans Jonas

\section{Considerações iniciais}

Como pensador de um monismo integral, Hans Jonas articula a razão e o afeto como dois lados de uma mesma moeda, ou seja, ambos são aspectos mutuamente complementares da ética. "Se não fôssemos receptivos ao apelo do dever em termos emotivos, mesmo a demonstração mais rigorosa e racionalmente impecável da sua correção seria impotente para produzir uma força motivadora"'.

A afirmação acima deixa claro que os afetos possuem um papel fundamental na ética de Hans Jonas. Segundo o autor, o sentimento de responsabilidade é a fonte de produção da disposição para reivindicar a existência das coisas através dos nossos atos. Para demonstrar a força de sua premissa, o autor utiliza o exemplo do cuidado parental como arquétipo da relação entre responsabilidade objetiva e o sentimento subjetivo de responsabilidade, "por meio do qual a natureza nos educou previamente e orientou nossos sentimentos para os tipos de responsabilidade aos quais falta a garantia do instinto"2.

Se o apelo ao sentimento de responsabilidade é visto como um dispositivo para reconhecer a dignidade do objeto da ética, outro afeto significativo na ética de Jonas é o temor. O autor atribui ao sentimento de temor em relação a um futuro catastrófico a

${ }^{1}$ JONAS, Hans. O Princípio Responsabilidade. Ensaio de uma ética para a civilização tecnológica. Tradução Marijane Lisboa. Rio de Janeiro: Contraponto - Ed. PUC Rio, 2011, p. 157.

${ }^{2}$ Ibidem, p. 164. 
utiliidade de um instrumento heurístico que pode ser usado a fim de evitar as ações que potencialmente nos conduziriam à destruição das condições de vida da humanidade futura, um tipo de "saber (que) se origina daquilo contra o que devemos nos proteger".

O imperativo categórico jonasiano, "aja de modo a que os efeitos de tua ação sejam compatíveis com a permanência de uma autêntica vida humana sobre a Terra", a heurística do temor são os instrumentos persuasivos mais marcantes de O Princípio Responsabilidade. Ambos representam a tentativa do autor em construir uma ética para a civilização tecnológica que contemple igualmente tanto o elemento racional quanto o afetivo, os quais se complementam na medida em que atingem as duas dimensões de determinação do agir.

Embora o sentimento de temor seja de grande importância para a compreensão da proposta ética de Jonas por configurar uma via heurística, devemos atentar para os demais afetos mencionados pelo autor em O Princípio Responsabilidade como pontos cruciais de sua proposta. Principalmente devemos ter em vista o que Jonas compreende por sentimento de responsabilidade e a sua gênese nas relações hiumanas.

Desta forma, abordaremos, além dos afetos de temor e de responsabilidade, os quais possuem um importantíssimo papel na teoria de Jonas, o funcionamento dos sentimentos de esperança, solidariedade, egoísmo e amor na ação ética. Com este espectro afetivo em vista, pretendemos compreender o lugar, bem como, os limites do apelo aos afetos humanos no constructo da ética para a civilização tecnológica.

\section{A importância da sensibilidade para a ação ética}

Em consonância com a tradição do pensamento ético, Hans Jonas postula que a razão deve se unir aos sentimentos para uma maior eficácia de sua influência sobre a ação ética, pois o agir necessita, também, de um elemento emocional que o oriente. Neste sentido, Jonas observa que Kant foi o único a fazer uma espécie de concessão à sensibilidade ao invés de admiti-la como parte integrante da ética ${ }^{5}$, motivo pelo qual o filósofo critica fortemente o formalismo kantiano.

Para Jonas, devido à nossa natureza sensível, a ética necessita de um objeto que inspire os humanos em sua direção. Ou como diz o autor: "a moral que supomos que deve se impor às emoções necessita, ela própria, de emoções"6. O autor cita o Eros platônico, o amor dei intellectuallis de Spinoza, a eudaimonia de Aristóteles, entre outros, como exemplos de determinação afetiva da ética em cada época. Embora esses objetos não sejam exatamente sensíveis, eles servem de dispositivo para a emoção necessária ao agir ético e podem ser contemplados como o summum bonum ou parte integrante dele. Assim, majoritariamente, remetem à ideia de algo atemporal e imperecível.

Já Hans Jonas, ao contrário dos pensadores mencionados, propõe que a emoção ou afetividade humana seja direcionada para um objeto perecível, sem o qual a própria continuidade do pensamento, possivelmente, será extinta. Este objeto é o ser humano genuíno, ou seja, o ser humano que vive sem intervenções excessivas da técnica em seus corpos e seu habitat. Ou ainda, que a nossa condição de existência no planeta Terra seja adequada aos humanos do porvir. $\mathrm{E}$ as condições de existência do ser humano genuíno englobam a existência dos seres vivos que também aqui habitam. Tendo isso em vista, segundo o filósofo, o sentimento adequado à determinação afetiva para o agir ético é a responsabilidade.

\section{Sobre o sentimento de responsabilidade}

\footnotetext{
${ }^{3}$ Tbidem, p. 71.

${ }^{4}$ Ibidem, p. 47.

${ }^{5}$ Embora Kant admita a necessidade de uma antropologia que auxilie o pensamento moral.

${ }^{6}$ JONAS, Hans. O Princípio Responsabilidade. Ensaio de uma ética para a civilização tecnológica. Tradução Marijane Lisboa. Rio de Janeiro: Contraponto - Ed. PUC Rio, 2011, p. 159. 
Conforme mencionado anteriormente, o papel dos afetos nas ações humanas já foi tema de alguns pensadores que se propuseram refletir sobre a ética. Todavia, temos no pensamento de Hans Jonas uma novidade sobre um tipo de sentimento que, conforme argumenta o autor, nunca foi evocado pelos filósofos para pensar o agir humano: a responsabilidade como afeto motivador da ação ética.

Apesar de Jonas distinguir entre tipos de responsabilidade em sua obra, passando pela responsabilidade legal de imputação causal por atos realizados, a principal função da responsabilidade no pensamento do autor está no seu poder afetivo.

Tradicionalmente, como observou Paul Ricouer em The Concept of Responsibility: An Essay in Semantic Analysis ${ }^{7}$, a responsabilidade foi considerada de forma majoritária como uma noção aplicada ao âmbito jurídico de imputação causal por atos que possam prejudicar outrem. No entanto, na contemporaneidade, esta noção se alargou e passou a figurar na categoria de conceito moral.

Podemos dizer que no pensamento de Jonas a responsabilidade pertence a um espectro de afetos ligados ao reconlhecimento "do bem em si do mundo", os quais são capazes de motivar a ação ética em prol da continuidade da existência humana na Terra. A disposição para ser afetado por este sentimento pertence a própria constituição humana segundo o autor, e, desta maneira, o uso do afeto de responsabilidade na teoria ética deve ser consumado como um apelo psicológico ao desejo humano ou vontade. Nas palavras do autor,

para que algo me atinja e me afete de maneira a influenciar minha vontade é preciso que eu seja capaz de ser influenciado por esse algo. Nosso algo emocional tem de entrar em jogo. E é da própria essência da nossa natureza que a nossa intelecção nos transmita um apelo que encontre uma resposta em nosso sentimento. 茞 o sentimento de responsabilidade. ${ }^{10}$

Isto significa que, para Jonas, a existência dos sentimentos e da sensibilidade humana configura "presumivelmente un potencial humano universal"11 para a recepção apelativa do bem ético, o que torna a afetividade humana um "elemento cardinal da moral"12. A existência deste potencial revelaria que a aptidão moral dos humanos passa necessariamente pelos sentimentos das subjetividades na medida em que "pertence ao sentido mais intrínseco do princípio normativo que o seu apelo se dirija àqueles que, por sula constituição natural, sejam receptíveis a ele ${ }^{p 13}$, mesmo que não haja garantias de seu cumprimento. Desta forma, "os humanos são seres morais potenciais porque possuem essa capacidade de ser afetados, e só por isso também podem ser imorais". 14

Conforme mencionamos anteriormente, o afeto na ética de Hans Jonas difere das éticas anteriores, nas quais o objeto do afeto muitas vezes possuía um status atemporal correlacionado com o transcendente ${ }^{15}$, pois tem como objeto o perecível, a fragilidade da continuidade dos modos de vida humana dignos deste nome em tempos em que a potência tecnológica ameaça a destruição das condições de permanência da humanidade e de toda a comunidade de seres viventes do planeta.

Esse objeto tão distante de uma 'perfeição', em sua facticidade totalmente contingente, apreendida precisamente em seu caráter perecível, de carência e

\footnotetext{
${ }^{7}$ RICOUER, Paul. The concept of responsibility: an essay in semantic analysis. In: The Just. Transation David Pellauer. Chicago: University of Chicago Press, 2000.

${ }^{8}$ JONAS, Hans. O Princípio Responsabilidade. Ensaio de uma ética para a civilização tecnológica. Tradução Marijane Lisboa. Rio de Janeiro: Contraponto - Ed. PUC Rio, 2011, p. 156.

${ }^{9}$ A responsabilidade parental é um indicativo da manifestação constitutiva deste afeto.

${ }^{10}$ JONAS, Hans. O Princípio Responsabillidade. Ensaio de uma ética para a civilização tecnológica. Tradução Marijane Lisboa. Rio de Janeiro: Contraponto - Ed. PUC Rio, 2011, p. 156 - 157.

${ }^{11}$ Ibidem, p. 157.

${ }^{12}$ Ibidem

${ }^{13}$ Ibidem

${ }^{14}$ Ibidem, p. 158.

${ }^{15}$ A eudaimonia em Aristóteles e o Eros platônico, por exemplo.
} 
innseguirança, é que é capaz de, graças a sua mera existência, colocar-ine à sua disposição, livre de qualquer pretensão de apropriação. Evidentemente, ele tem esse poder, pois de outra forma não haveria tal sentimento de responsabilidade em relação à sua existência. Ora, esse sentimento existe como um fato empírico e não é menos verdadeiro do que os sentimentos sensualistas da experiência do summum bonum. ${ }^{16}$

O perecível de Jonas é o Ser ${ }^{17}$, mais precisamente a sua manifestação como ser vivo que expressa uma diversidade de níveis da liberdade orgânica, a qual culmina na expressão humana da liberdade. Para o autor, a lei moral não é causa nem objeto de respeito, mas antes, o próprio "Ser que, reconhecido em sua plenitude ou em uma das suas manifestações particulares, (...) pode efetivamente impor respeito, e com essa sua capacidade de influenciar nossos sentimentos vir em socorro da lei moral"18.

Por sua vez, a lei moral no pensamento de Jonas configura a "lei que ordena que o nosso próprio Ser satisfaça a reivindicação imanente daquele que existe"19. No entanto, no exercício da reivindicação do Ser não basta somente o respeito e sim o afeto que nasce da responsabilidade pela sua continuação. Desta maneira, Jonas identifica o sentimento de responsabilidade como o elo que liga o agente ao objeto do agir ético: "esse sentimento, mais do que qualquer outro, é capaz de produzir em nós a disposição de apoiar a reivindicação de existência do objeto por meio da nossa ação" ${ }^{20}$

Assim, a responsabilidade, tão solicitada e necessária ao nosso tempo se mostra como o instrumento afetivo principal da ética para a civilização tecnológica, mais do que o famoso afeto político do temor.

O poder do sentimento de responsabilidade, possivelmente, encontra-se na sua gênese, pois está enraizado no íntimo do instinto de procriação e continuidade humana, já que é um afeto espontâneo da relação parental a qual não exige nenhuma obrigação recíproca. "Essa é a única classe de comportamento inteiramente altruísta fornecida pela natureza". 21

Para Jonas, esta é a origem genuína da responsabilidade e de suas implicações. "Aqui se encontra o arquétipo de todo agir responsável, que por sorte não necessita deduzir qualquer princípio, mas que a natureza plantou solidamente em nós" que haja uma diferença entre o dever para com os fillhos e o dever em relação às gerações futuras. Pois, o agir responsável por meio de ações que visem a existência das gerações futuras deve ser executado independentemente da existência de descendentes do agente entre os futuros humanos.

Não podemos deixar de observar que para o autor, embora o afeto de responsabilidade seja, até mesmo, a precondiçăo da moral, a responsabilìdade necessariamente exige um objeto para não se tornar mera formalidade incapaz de arcar com o princípio da ação ética.

O sentimento que caracteriza a responsabilidade - não importa se pressentimento ou reação posterior - é de fato moral, mas em sua formalidade pura não é capaz de fornecer o princípio efetivo para a teoria ética, que em primeira e última instância tem a ver com a apresentação, reconhecimento e motivação de finalidades positivas para o bonum huimanum. Da inspiração desses fins, do efeito do bem sobre o sentimento pode brotar a disposição de assumir responsabilidades. ${ }^{23}$

${ }^{16}$ JONAS, Hans. O Princípio Responsabilidade. Ensaio de uma ética para a civilização tecnológica. Tradução Marijane Lisboa. Rio de Janeiro: Contraponto - Ed. PUC Rio, 2011, p. 159 - 160.

17 "O Ser, ou a natureza, é uno e presta testemunho de si naquilo que permite emergir de si". Ibidem, p. 134.

${ }^{18}$ Ibidem, p. 163.

${ }^{19}$ Ibidem

${ }^{20}$ Ibidem

${ }^{21}$ Ibidem, p. 89

22 Ibidem, p. 90.

${ }^{23}$ Ibidem, p. 166 
Desta maneira, apenas "ser responsável" sem ter em vista ự objeto próprio não garante a efetividade da ação, que necessita de uma motivação advinda do objeto em questão, no caso, o reconhecimento da existência da humanidade futura como um valor que deve ser almejado e visado pelas práticas humanas.

O sentimento de responsabilidade, neste caso, extrapola a referência subjetiva a um sujeito que se sente responsável pela sua própria conduta e encontra o seu referente na esfera de influência de seu poder de ação, na medida em que, "ao meu poder ele (o referente) contrapõe o seu direito de existir como é ou poderia ser, e com a vontade moral ele submete o meu poder. O objeto se torna meu, pois o poder é meu e tem um nexo causal com esse objeto"24.

Temos, então, a vontade como a operadora do reconhecimento da dignidade do referente o qual recebe os efeitos da ação de meu poder causal. "O poder se torna, assim, objetivamente responsável por aquele que lhe foi confiado e afetivamente engajado graças ao sentimento de responsabilidade: no sentimento, aquele que obriga encontra seu nexo com a vontade subjetiva", 25

Ao que indica Jonas, o papel da vontade possui uma enorme importância na ocorrência do afeto de responsabilidade nos seres humanos, pois o autor nos leva a crer que ela participa do reconhecimento do valor do objeto em questão, enquanto o sentimento despertado passa a funcionar como elo de ligação entre a vontade do agente e o referente ou objeto ético ${ }^{26}$. O autor afirma que: "a tomada de partido sentimental tem sua primeira origem não na ideia de responsabilidade em geral, mas no reconhecimento do bem intrínseco do objeto, tal como ele influencia a sensibilidade"27. Desta forma, a influência do objeto sobre a sensibilidade é compreendida como uma espécie de reivindicação de existência devido a sua fragilidade perante o poder causal do agente. A tomada de consciência de seu próprio poder aniquilador por parte do agente, juntamente com a influência sensível do objeto, "unem-se no sentimento de responsabilidade afirmativa do eu ativo, que se encontra sempre intervindo no Ser das coisas". 28

Portanto, a suscitação do sentimento de responsabilidade está profundamente ligada à sensibilização da vontade quanto à fragilidade e dignidade do objeto em questão, como também, do reconhecimento do poder causal do agente em relação a tal objeto. Isto quer dizer que, de modo estrito, os objetos capazes de suscitar o afeto de responsabilidade possuem naturalmente unna ligação que repercute em imputação de cuidado por parte do agente (como, por exemplo, a responsabilidade parental), ou são capazes de sensibilizar o portador do poder causal relativo a sua existência pela força da representação de sua dignidade e valor na iminência de sua ameaça existencial.

\section{Sobre o temor}

O temor ou medo é um dos afetos políticos mais famosos na tradição filosófica. A ele, comumente, é associado o poder de controle das massas humanas, seja pela opressão advinda de um governante forte que inspira medo para poder diminuir a força de ação dos indivíduos pelo enfraquecimento de seus conatus, para Spinoza. Seja como um agregador social para Hobbes, que considera este o afeto político central de sua teoria sobre a causa que nos levou a abandonar o estado de natureza e nos agregarmos em conglomerados sociais humanos.

Na ética de Jonas, o temor tem uma função inusitada, ele funciona como um afeto capaz de promover o conhecimento das situações indesejáveis a serem evitadas pelos humanos, ou seja, possui um sentido heurístico sobre situações extrapoláveis que

\footnotetext{
${ }^{24}$ Ibidem, p. 167

${ }^{25}$ Ibidem

${ }^{26}$ Discutiremos mais a frente sobre o lugar da vontade no pensamento de Jonas. Por hora, nos concentraremos na exposição dos afetos en sua obra.

27 JONAS, Hans. O Princípio Responsabilidade. Ensaio de uma ética para a civilizacão tecnológica. Traducão Marijane Lisboa. Rio de Janeiro: Contraponto - Ed. PUC Rio, 2011 , p. 167.

28 Ibidem
} 
estão sob o poder da ação humana. "O que nós não queremos, sabemos muito antes do que aquilo que queremos. Por isso, para investigar o que realmente valorizamos, a filosofia da moral tem de consultar o nosso medo antes do nosso desejo" 29

Os perigos e desafios da contemporaneidade não possuem precedentes na história da humanidade, nunca a existência humana se viu ameaçada pelo seu próprio poder de intervenção. Nesta ótica, Jonas encara como urgente a tomada de postura ética em relação a um futuro catastrófico, ou seja, consultar o nosso medo ao invés do nosso desejo pode ser uma saída diante da expectativa da desfiguração da Terra e da existência que consideramos humana ${ }^{30}$

A função heurística que Jonas atribui ao temor pode ser encarada como uma tentativa de compreensão possível, e ao alcance de todos, sobre a ameaça que o uso desregrado das tecnologias pode acarretar. É uma maneira simplificada de compreender o que está em jogo em nosso tempo. Já que "enquanto o perigo for desconhecido não se saberá o que há para se proteger e por que devemos fazê-lo"31. Pois, compreender a complexidade dos fenômenos os quais estamos submetidos é uma tarefa que exige uma gama de conhecimentos que tomam a discussão sobre o ethos civilizatório bem distante da grande parte dos humanos comuns.

Jonas pauta o seu argumento no funcionamento do comportamento humano no que concerne ao conhecimento da sua situação existencial:

o reconhecimento do malum é infinitamente mais fácil do que o do bonum; é mais imediato, mais urgente, beim menos exposto a diferenças de opinião; acima de tudo, ele não é procurado: o mal nos impõe a sua simples presença, enquanto - bem pode ficar discretamente ali e continuar desconhecido, destituído de reflexão. Não duvidamos do mal quando com ele nos deparamos. ${ }^{32}$

Obviamente, como uma solução simples para um problema complexo, a heurística do temor possui a sua vulnerabilidade. A nobreza de seu uso pode se voltar contra o ideal de sua proposta. O que pode ser indesejado por alguns, visto a descaracterização do ser humano como objeto da técnica, pode ser visto por outros com desejo de superação da espécie por meios técnicos. Por isso, Jonas recorre a um suposto pavor gerado pela ameaça à imagem humana para afirmar uma imagem do ser humano que seja autêntica. "Precisamos da ameaça à imagem humana - e de tipos de ameaça bem determinados" ${ }^{\prime \prime 3}$. Nos parece que a força da argumentação está justamente na determinação da espécie da ameaça, pois, conforme mencionamos acima, algum tipo de transhumanismo ${ }^{34}$ pode ser desejável para alguns em nome de uma melhoria na performance do humano. Há, todavia, uma certa confusão quanto ao que vem a ser uma existência humana autêntica. Para Jonas, isto significa modos de existir sem o excesso de intervenção de subterfúgios tecnológicos. Podemos tomar como exemplo o limite entre a profilaxia e o melhoramento na medicina, embora este limite seja, muitas vezes, difícil de estabelecer e gere muita discussão na sua determinação.

É possível que, para o funcionamento efetivo da heurística do temor, seja necessário se utilizar de uma multiplicidade de diferentes imagens que potencialmente poderiam causar o sentimento esperado por Jonas. De fato, não é qualquer temor o

\footnotetext{
${ }^{29}$ Ibidem, p. 71.

${ }^{30} \mathrm{~A}$ ameaça a desfiguração do humano via biotecnologias é o tema que impulsionou o filósofo a escrever a obra o Princípio Responsabilidade.

${ }^{31}$ Tbidem, p. 70-71.

32 Ibidem, p. 71

${ }^{33}$ Ibidem, p. 70

${ }^{34}$ Lilian Godoy Fonseca aponta em sua tese de doutorado sobre Hans Jonas e a responsabilidade do homem frente ao desafio biotecnológico a abordagem transhumanística como "segundo a qual o corpo pode ser desmontado e reprogramado para facilitar a substituição de alguma parte por um aparato tecnológico". Cf. FONSECA, Lilian S. Godoy. Hans Jonas e a responsabilidade do homem frente ao desafio biotecnologico. Tese (Doutorado em Filosofia) - Faculdade de Filosofia e Ciências Humanas (FAFICH), Universidade Federal de Minas Gerais - UFMG, Belo Horizonte 2009, p. 54.
} 
sentimento defendido pelo filósofo. Conforme destaca Lilian Godoy Fonseca, o temor jonasiano é um afeto que nos leva a agir, ele não nos paralisa e tampouco é patológico, como no caso do medo hobbesiano, mas sim é caracterizado pelo afeto "de um sujeito que teme pelo destino do outro" ${ }^{\prime 35}$. Até mesmo, devido a sua natureza opressora, metaforicamente pode ser tomado como "o mesmo princípio usado pelo soro que extrai do próprio veneno o seu antídoto" ${ }^{m 6}$.

Justamente por considerar o temor eficaz como instrumento do princípio de precaução, Jonas propõe o seu uso metodológico na previsão hipotética da desfiguração da imagem do humano (como dissemos acima, possivelmente, há variações sobre o que isso vem a ser). Desta maneira, o temor possui um papel fundamental na suscitação da visualização dos efeitos da desfiguração humana, a qual figura como "o primeiro dever da ética do futuro"37. Este dever é compreendido da seguinte forma:

O que deve ser temido ainda não foil experimentado e talvez não possua analogias na experiencia do passado e do presente. Portanto, o malum imaginado deve aquil assumir o papel do malum experimentado. Como essa representação não acontece automaticamente, ela deve ser produzida intencionalmente: portanto, obter uma projeção desse futuro torna-se um primeiro dever, por assim dizer introdutório, daquela ética que buscamos. ${ }^{38}$

Isto significa que, como método, o afeto do temor é aliado à esfera da racionalidade humana, já que deve ser suscitado por um ato intencional ${ }^{39}$. Ou seja, o método heurístico consiste justamente em utilizar a potencialidade inerente ao afeto de temor sob o comando de uma intenção que deseja evitar um mal maior.

Após invocar uma imagem catastrófica de desfiguração do ser humano, o temor novamente entra em cena para a mobilização adequada dos afetos. Jonas considera esta segunda etapa de suscitação do temor como "o segundo dever: (o de) mobilizar o sentimento adequado à representação"

O apelo afetivo de Jonas nesta etapa do processo heurístico de conhecimento do mal futuro se justifica pelo fato de uma representação invocada pela imaginação, e projetada como um futuro possível, não possuir o mesmo efeito de üma representação experimentada na realidade pelo agente. "Esse malum imaginado, não sendo o meu, não produz o medo da mesma forma automática como o faz o malum que eu experimento e que me ameaça pessoalmente ${ }^{n+41}$. Desta forma, o autor coloca como um dever mobilizar o afeto de temor como se o próprio agente pudesse antever no presente as consequências dos efeitos das ações que ameaçam a integridade humana no futuro. Esta atitude é caracterizada por um tipo de temor espiritual em relação as condições de existência da humanidade futura. Este é o sentido de adequação afetiva proposta por Jonas.

A adoção dessa atitude, ou seja, a disposição para se deixar afetar pela salvação ou pela desgraça (ainda que só imaginada) das gerações vindouiras é o segundo dever 'introdutório' da ética almejada, após o primeiro, que é o de, acima de tudo,

\footnotetext{
${ }^{35}$ FONSECA, Lilian S. Godoy. Hans Jonas e a responsabilidade do homem frente ao desafio biotecnológico. Tese (Doutorado em Filosofia) - Faculdade de Filosofia e Ciências Humanas (FAFICH), Universidade Federal de Minas Gerais - UFMG, Belo Horizonte 2009, p. 418.

${ }^{36}$ Tbidem

${ }^{37}$ JONAS, Hans. O Princípio Responsabilidade. Ensaio de uma ética para a civilização tecnológica. Tradução Marijane Lisboa. Rio de Janeiro: Contraponto - Ed. PUC Rio, 2011, p. 72.

${ }^{38}$ Ibidem

${ }^{39}$ A intencionalidade humana se apresenta no pensamento de Jonas como a manifestação mais livire da mesma capacidade presente em todas as formas de vida, mesmo nas mais simples. Na esfera humana, a intencionalidade se relaciona com a racionalidade na medida em que, por serem mediados por representações, os humanos possuem a capacidade de suscitar uma intenção livremente e não somente serem guiados pela intençăo em perseverar na existência.

${ }^{40}$ JONAS, Hans. O Princípio Responsabilidade. Ensaio de uma ética para a civilização tecnológica. Tradução Marijane Lisboa. Rio de Janeiro: Contraponto - Ed. PUC Rio, 2011, p. 72.

${ }^{41}$ Ibidem
} 
produzir tal pensamento. Instruídos por este, somos instados a evocar o temor correspondente ${ }^{42}$

É necessário levar em consideração que o método da heurística do temor de Jonas considera como objeto as situações extrapoláveis que possuam respaldo científico. "Assim como os empreendimentos (cujas consequências posteriores devemos conhecer pela extrapolação) só se viabilizam por meio da ciência, da mesma forma essa extrapolação requer, no mínimo, o mesmo grau de ciência utilizado"43. Ou seja, o temor que deve ser suscitado necessariamente tem de possuir uma fundamentação científica forte o suficiente para se consolidar.

No entanto, observemos que, devido à complexidade de alguns fenômenos da natureza e mesmo humanos, o grau de certeza científica é sempre discutível, por exemplo, "a complexidade das relações causais na ordem social e na biosfera, que desafia qualquer cálculo"4. Mesmo neste cenário, a extrapolação proposta por Jonas "exige um grau de ciência maior do que o que já existe no extrapolandum tecnológico" 45.

Isso quer dizer que o tipo de saber relativo ao que devemos temer se produz tanto com as ciências duras quanto com a extrapolação filosófica, mas não se restringe ao grau de certeza da primeira, pois o "saber sobre as possibilidades, certamente insuficiente para previsões, é suficiente para os fins da casuística heurística" ${ }^{\text {"46 }}$, na medida em que as conjecturas possuem um papel importante no experimento mental da extrapolação de uma situação apontada como possível pela ciência.

Os seus recursos são experimentos de pensamento não somente hipotéticos na aceitação das premissas, mas também conjecturais na dedução de um se para um então. É à luz do 'então', que se apresenta à imaginação como possibilidade, como conteúdo e não como certeza, que pela primeira vez os princípios da moral, até ali desconhecidos, porque antes desnecessários, podem tornar-se visíveis. ${ }^{47}$ (PR, p. 74$)$.

Desta maneira, Jonas estabelece os dois primeiros deveres da Ética do Futuro a partir do sentimento de temor por entender que as imagens invocadas por este afeto possuem uma potencialidade muito útil no prognóstico das situações presentes que podem colocar a existência humana em perigo.

\section{A esperança}

A compreensão da esperança em O Princípio Responsabilidade deve ser pautada na crítica de Hans Jonas à utopia inserida na lógica de um progresso em direção a um futuro de benesses materiais que isentariam o trabalho humano apregoado por alguns teóricos, em especial, pelo marxista Ernst Bloch. Segundo Jelson Oliveira e Paulo Guimarães $^{48}$, Jonas considera a utopia a partir da ótica dos posicionamentos políticos progressista que desejam afirmar o poder humano conferido pela técnica como indiscutivelmente bom. "São elas (as políticas utópicas) que consolidam a ideia de que o homem está pretensamente seguindo o 'caminho certo'. Como 'políticas', elas são apoiadas em processos que lhes dão legitimidade social ${ }^{m 49}$. Um bom exemplo deste tipo

\footnotetext{
${ }^{42}$ Ibidem, p. 73 .

${ }^{43}$ Ibidem

${ }^{44}$ Ibidem

45 Ibidem

${ }^{46}$ Ibidem

${ }^{47}$ Ibidem, p. 74.

${ }^{48}$ OLIVEIRA, Jelson. GUIMARÃES, Paulo. A dimensão utópica da técnica modema: A critica de Hans Jonas ao programa baconiano e à teoria marxista. In: Problemata: Revista Internacional de Filosofia. João Pessoa: v. $7, \mathbf{n}$. 1, 2016, p.273-294.

49 Tbidem p. 278.
} 
de utopia é a ideia de um progresso material infinito da humanidade, que é legitimado socialmente pela ilusão da abundância material de nosso tempo.

Jonas ressalta que "a primeira condição da utopia é a abundância material, de modo a satisfazer as necessidades de todos; a segunda condição é a facilidade em adquiririr essa abundância"50 ( $\mathrm{PR}$, p. 299). Isto porque, segundo o autor, sendo a essência formal da utopia o lazer, a aquisiç̧ão e fomento da abundância "podem ser obtidos pela radicalização da técnica avançada" servidão do trabalho"52. A concretização deste ideal, da abundância de recursos aliada à auitomação das tarefas, é algo que, aparentemente, está em curso no nosso atual sistema econômico. Isto desperta o sentimento de esperança em um futuro utópico, no qual os indivíduos desfrutarão dos prazeres de um mundo de lazer e não de trabalho.

Justamente a ideia de algo "em curso" ou "no caminho certo" alimenta o ideal utópico de que "todo o passado é uma etapa preparatória para o presente e de que todo o presente é uma etapa preparatória para o futuro" ${ }^{\circ 3}$ próspero do lazer em substituição ao trabalho.

Quando essa representação (que, sendo illimitada, não privilegia nenhuim estado definitivo, deixando a cada um a imediaticidade do presente) liga-se a uma escatologia secularizada que atribui ao absoluto, definido em termos seculares, um lugar demarcado no tempo - a isso se acrescentando a concepção de uma dinâmica teleológica que conduiz ao estado definitivo -, então estão dados os pressupostos teóricos para a política utópica. ${ }^{54}$

A política utópica, por sua vez, utiliza-se do afeto de esperança na concretização do futuro ideal, traduzido pela imagem da prosperidade e do lazer futuro, no qual o "estado da ciência e da técnica, em todas as regiões onde elas se desenvolvem, indicam um progresso continuo e seguro, além de novos saltos tecnológicos ${ }^{n 55}$ para alimentar a crença em um desenvolvimento acrítico da sociedade de consumo. No entanto, esta utopia desenvolvimentista parece não se perguntar pelos limites materiais do planeta Terra.

Conforme pontua Jonas, "a questão é saber como a natureza reagirá a essa agressão intensificada" 56 . Em outras palavras, a questão que se coloca diz respeito à intensidade da catástrofe causada pelo grau de interferência dos humanos nos sistemas naturais da Terra e qual será a sua resposta.

Tais limites só se tornam perceptíveis quando os efeitos nocivos das nossas intervenções começam a afetar os ganhos e ameaçam superá-los. Os limites são ultrapassados, talvez sem volta atrás, quando esses esforços unilaterais arrastam o sistema inteiro, dotado de um equilílbrio múltiplo e delicado, para uma catástiofe do ponto de vista das finalidades huimanas. (A natureza, como tal, não conhece nenhuma catástirofe). 苂 uma descoberta relativamente recente não só a de que tal coisa pode acontecer em princípio, do ponto de vista das leis físicas, imas que, para esta nave Terra estritamente limitada, tal catástrofe possa ser o resultado direto das agressões que o homem lhe venha a fazer ou já esteja fazendo. ${ }^{57}$

\footnotetext{
${ }^{50}$ JONAS, Hans. O Princípio Responsabilidade. Ensaio de uma ética para a civilização tecnológica. Tradução Marijane Lisboa. Rio de Janeiro: Contraponto - Ed. PUC Rio, 2011, p. 299.

${ }^{51}$ Ibidem

52 Tbidem

${ }^{53}$ Ibidem, p. 55

${ }^{54}$ Ibidem

${ }^{5}$ Ibidem, p. 299.

${ }^{56}$ Ibidem, p. 300.

${ }_{57}$ Ibidem, p. 301
} 
Isto configura uma situação que não foi experimentada pela humanidade pretérita e, talvez, até mesmo inusitada para os teóricos do final do século XIX e início do século XX.

O elogio à utopia criticado mais ferozmente por Jonas veio de seu contemporâneo, Ernst Bloch ${ }^{58}$, por seu Princípio Esperança, escrito entre 1938 e 1947. De acordo com Jonas, a esperança é concebida por Bloch como "o último motivo propulsor da empreitada marxista"59, por ser tão grandiosa que ultrapassa qualquer outra virtude humana. Neste sentido, a esperança caracteriza não somente um afeto humano, mas aparece uma espécie de princípio de determinação da realidade na medida em que impulsiona a ação em direção ao porvir almejado. Ou como diz Jonas, esse algo novo almejado pode funcionar como "ideia reguladora na lógica e no pathos do argumento utópico" 60 .

Neste sentido, a esperança é discutida em O Princípio Responsabilidade não propriamente como afeto político, mas antes como um tipo de princípio ontológico que rege uma escatologia secularizada, que potencialmente representa uma ameaça à ideia de austeridade necessária à ação ético-política global face os desafios ecológicos que se mostram como efeitos reais da intervenção excessiva dos seres humanos nos sistemas naturais. A esperança utópica impulsionadora de uma sociedade do lazer, como queria Bloch, é incompatível com os limites planetários, conforme demonstrou Jonas em sua crítica. Desta maneira, a ilusão gerada por este ideal se mostra como perigosa por extrapolar as reais condições materiais do planeta, embora, na prática, estejamos agindo contemporaneamente como se estivéssemos aspirando por sua realização.

\section{A solidariedade e o amor}

Jonas fala pouco sobre estes afetos em O Princípio Responsabilidade, todavia, a solidariedade é uma peça chave para compreender a Ética do futuro, já que o seu núcleo é justamente a preservação das condições de existência da humanidade futura digna deste nome. Ou seja, a responsabilidade pelas gerações vindouras requer como condição de possibilidade o afeto de solidariedade em relação ao futuro dos que virão, que se traduz em uma espécie de amor pela humanidade.

O autor encontra um paralelo entre o sentimento de solidariedade no campo político com o amor, sentimento característico da responsabilidade parental e, portanto, da esfera privada, por considerar que é possível "uma identificação emocional com o coletivo", a qual gera "o sentimento de solidariedade, que é análogo ao amor pelos indivíduos"61. Desta maneira, tanto o amor na esfera privada quanto a solidariedade na esfera pública funcionariam como dispositivos para a afetividade ética. "O fenômeno do sentimento torna o coração receptível ao dever, não lhe questionando a razão e animando a responsabilidade assumida com o seu élan. É difícil, senão impossível, assumir a responsabilidade por algo que não se ame"

Outra esfera da solidariedade tratada por Jonas se refere à solidariedade de interesses dos seres humanos com os demais seres orgânicos e a responsabilidade humana pela existência destes. O autor vê esta questão por duas vias: por um lado, o futuro do mundo orgânico é a condição sine qua non da preservação das condições de existência dos humanos. Por outro, mesmo que existisse a possibilidade de os humanos viverem em um mundo no qual a biosfera perdeu grande parte de sua diversidade,

\footnotetext{
${ }^{58}$ Filósofo alemão (1885-1977) hegeliano-marxista conhecido principalmente pelos seus escritos sobre a utopia, sobre o "ainda não". O autor foi um dos expoentes das correntes espirituais gnósticas e apocalípticas do início do século XX na Alemanha. Este fato pode ter contribuído para o posicionamento crítico de Jonas em relação a sua filosofia. Disponível em: Ernst Bloch Zentrum: http:/www.bloch.de/wissenschaft/wer-ist-ernstbloch/philosophie/.

${ }^{59}$ JONAS, Hans. O Princípio Responsabilidade. Ensaio de uma ética para a civilização tecnológica. Tradução Marijane Lisboa. Rio de Janeiro: Contraponto - Ed. PUC Rio, 2011, p. 315.

${ }^{60}$ Tbidem, p. 310.

${ }^{61}$ Tbidem, p. 183.

${ }^{62}$ Ibidem
} 
teríamos "uma responsabilidade metafísica, na medida em que o homem se tornou perigoso não só pra si, mas para toda a biosfera"63. Neste sentido, Jonas pondera que a natureza "teria o direito de reclamar a nossa proteção" ${ }^{64}$, dada a sua dignidade.

No entanto, a situação hipotética de uma separação real entre humanos e natureza, ao que tudo indica, está descartada. O destino dos humanos parece estar inegavelmente atrelado ao destino do mundo natural na medida em que as condições de existência humana dependem da disponibilidade da natureza. Isto quer dizer que a desfiguração da natureza acarretará a desfiguração do que concebemos como humano.

Como é impossível separair esses dois planos sem desfigurar a imagem do humano, e como naquilo que é mais decisivo - a saber, na alternativa "preservação ou destruição" - os interesses humanos coincidem com o resto da vida, que é sua pátria terrestre no sentido mais sublime da expressão, podemos tratar as duas obrigaçoes sob o conceito-chave de dever para com o humano, sem incorrer em um reducionismo antropocêntrico. ${ }^{65}$

Para Jonas, o dever para com o ser humano inclui o dever para com o mundo natural porque uma humanidade digna só é concebível como parte deste mundo, o qual deve ser preservado da interferência excessiva da técnica e de seus efeitos por estar ameaçado pela possibilidade de uma desfiguração tão extrema que tornará árdua a subsistência de grande parte da vida, principalmente a animal.

O filósofo considera que o reducionismo antropocêntrico desumaniza o ser hhumano na medida em que o coloca em um perigoso patamar de distância e diferença da natureza. Isto "significa apenas reduzir e desumanizar o homem, pois a atrofia da sua essência, na hipótese mais otimista da sua preservação biológica, contradiz o seu objetivo expresso, a sua preservação sancionada pela dignidade do seu Ser ${ }^{\circ 66}$. Ou seja, o reducionismo antropocêntrico pode levar a humanidade a contradizer a premissa básica de seus atos, que é garantir a sua própria existência e bem-estar.

A solidariedade de destino gerada pelo poder destrutivo da humanidade via tecnologia, afirma Jonas, "nos permite descobrir novamente a dignidade própria da natureza, conclamando-nos a defender os seus interesses para além do aspecto utilitário"67. Reconhecer a dignidade da natureza, neste sentido, é não interferir excessivamente em suas leis internas, pois o seu equilíbrio sutil é regulado por estas. Como observa o autor, até pouco tempo atrás, mesmo a intervenção humana não era considerada ameaçadora do equilíbrio ecológico porque "a severa lei da ecologia impedia toda a pilhagem excessiva de uma espécie por outra"68. Todavia, este quadro mudou de maneira radical com os saltos tecnológicos do século XX e XXI.

Mesmo que a dignidade da existência do mundo natural seja reconhecida como um bem em si mesmo, já que fazemos parte da natureza e "na medida em que ela nos gerou, devemos fidelidade à totalidade de sua criação"69, Jonas pontula que a solidariedade de interesse com o mundo orgânico está pautada, em última instância, na preservação das condições de existência da própria humanidade.

O caminho tomado por Jonas consiste em reforçar a necessidade política de suscitar a solidariedade em relação aos humanos do futuro muito mais do que a solidariedade em relação ao destino do mundo natural. Pois, tal argumento, além de necessariamente incluir a natureza devido à solidariedade de destino, parece possuir mais força afetiva quanto à mobilização em prol da conservação da própria espécie. Entretanto, contemporaneamente, este tipo de amor a ser despertado nos humanos por si mesmos, pela sula continuidade como espécie, parece não exercer a força afetiva

\footnotetext{
${ }^{63}$ Ibidem, p. 229

64 Ibidem.

${ }^{65}$ Ibidem

${ }^{66}$ Ibidem

${ }^{67}$ Ibidem, p. 230.

68 Ibidem.

${ }^{69}$ Ibidem, p. 229
} 
esperada e necessária à mudança de paradigma em uma parte significativa da comunidade humana.

\section{Considerações finais}

A análise dos afetos em O Princípio Responsabilidade possibilitou esclarecermos os potenciais dos afetos que, segundo Jonas, devemos mobilizar para a ação ética que vise a manutenção das condições de existência da humanidade futura. Com este conhecimento de nossa base afetiva foi possível refletir sobre a real possibilidade de realizar essa mobilização.

Como vimos acima, os sentimentos possuem diferentes nuances no pensamento de Jonas, a responsabilidade, por sula vez, é considerada o afeto central da Ética do Futuro enquanto o temor serve como um dispositivo heurístico. No entanto, podemos afirmar que o amor e a solidariedade são essenciais aos objetivos propostos pelo autor.

A grande questão que desafia a Ética do Futuro está justamente no campo do desejo humano do conforto imediato. Em uma sociedade na qual o conforto está ligado de maneira muito profunda à tecnologia contemporânea, a tarefa de convencimento da sociedade a consultar antes o medo em relação ao futuro da humanidade do que o desejo em continuar usufruindo das benesses tecnológicas se apresenta árdua. Todavia, o sentimento de temor, ao que aponta Jonas, é tão profundo e funcional em nossa constituição que nele nos resta uma possibilidade de enfrentamento desta situação.

O temor o qual se refere Jonas tem as suas origens no medo característico da nossa animalidade e possui uma força ancestral e profunda na direção da preservação dos seres animais. O medo, afeto característico da presença física de algo assustador, tem o seu sentido expandido no fenômeno do temor virtual a algo indesejado que pode ou não se concretizar.

Quanto ao sentimento de amor, Jonas pouco teoriza em sua proposta ética e em sula ontologia, no entanto, temos que considerar a influência deste afeto na ação dos indivíduos segundo o pensamento do autor. Pois Jonas postula uma ligação estreita entre o amor e o sentimento de responsabilidade.

Já o afeto de solidariedade, embora aparentemente não possua a potência necessária à mudança nas ações coletivas em direção à uma existência mais integrada com a natureza, é o sentimento que pode nos manter unidos politicamente para resistirmos à imposição de práticas que possam desfigurar geneticamente a existência humana como conhecemos.

Quem sabe a proximidade da catástrofe possa despertar o tipo de temor sugerido por Jonas. Nos resta saber se haverá tempo...

\section{Referências}

JONAS, Hans. O Princípio Responsabilidade. Ensaio de uma ética para a civilização tecnológica. Tradução Marijane Lisboa. Rio de Janeiro: Contraponto - Ed. PUC Rio, 2011.

Técnica, Medicina e Ética. Sobre a Prática do Princípio Responsabilidade. São Paulo: Paulus, 2013.

. The Imperative of Responsability. In a Search of na Ethics for the Tecnological Age. Chicago: The University of Chicago Press, 1985.

The Phenomenon of Life: Towards a Philosophical Biology. Evanston:

Northwestern University Press, 2001.

OLIVEIRA, Jelson. LAZARETTI, Lucas P. Abraão e Isaac: os sacrifícios do presente e os benefícios do futuro. Pensando - Revista de Filosofia, Teresina, vol. 7, № 14, 2016. 
OLIVEIRA, Jelson. GUIMARÃES, Paulo. A dimensão utópica da técnica moderna: A crítica de Hans Jonas ao programa baconiano e à teoria marxista. In: Problemata: Revista Internacional de Filosofia. João Pessoa: v. 7, n. 1, 2016, p.273-294.

RICOUER, Paul (1992) The concept of responsibility: an essay in semantic analysis in The Just, transation David Pellauer, University of Chicago Press, Chicago, 2000.

Doutora em Filosofia (PŪC-Rio) Professora Colaboradora do PPG em Filosofia/UFRRJ

E-maill: michellebobsin@yahoo.com.br 